\title{
SOME HILBERT SPACE CHARACTERIZATIONS AND BANACH SPACE INEQUALITIES
}

\author{
TAE-HWA KIM* AND HONG-KUN XU **
}

\begin{abstract}
It is well known that if $X$ is a normed linear space with dimension not less than three such that the radial projection from $X$ onto the closed unit ball is nonexpansive, then $X$ must be an inner product space. Using this fact, we are able to give a characterization of Hilbert spaces. Two other Hilbert space characterizations and some Banach space inequalities are established via duality maps.
\end{abstract}

Mathematics subject classification (1991): Primary 46B20; Secondary 47H09.

Key words and phrases: Radial projection, nonexpansive mapping, condition A, duality map, uniformly smooth Banach space, inequality.

\section{REFERENCES}

[1] F. E. BROWDER, Convergence of approximants to fixed points of nonexpansive nonlinear maps in Banach spaces, Arch. Rational Mech. Acad. 24 (1967), 82-90.

[2] R. E. BRUCK, The iterative solution of the equation $y \in x+T x$ for a monotone operator $T$ in Hilbert space, Bull. Amer. Math. Soc. 79 (1973), 1258-1261.

[3] J. CIORANESCU, Geometry of Banach Spaces-Duality Mappings and Nonlinear Problems, Mathematics and Its Applications 62, Kluwer Academic Publisher, Dordrecht, The Netherlands, 1990.

[4] D. G. DefigueIREDO AND L. A. KARLOVITZ, On the radial projection in normed spaces, Bull. Amer. Math. Soc. 73 (1967), 364-368.

[5] J. Diestel, Geometry of Banach Spaces-Selected Topics, Lect. Notes in Mathematics 485, Springer-Verlag, New-York, 1970.

[6] B. HARPERN, Fixed points of nonexpanding maps, Bull. Amer. Math. Soc. 73 (1967), 957-961.

[7] K. KIM AND S. S. SHIN, On approximating fixed points in Banach spaces, Preprint.

[8] J. A. PARK, Mann-iteration process for the fixed point of strictly pseudocontractive mapping in some Banach spaces, J. Korean Math. Soc. 31 (1994), 333-337.

[9] J. A. PARK, Mann-iteration process to the solution of $y=x+T x$ for an accretive operator $T$ in some Banach spaces, Comm. Korean Math. Soc. 9 (1994), 819-823.

[10] S. P. Singh AND B. Watson, On approximating fixed points, Proc. Symp. Pure Math. 45 (1986), Part 2, 393-395.

[11] H. K. XU, Inequalities in Banach spaces with applications, Nonlinear Analysis 16 (1991), 1127-1136.

[12] H. K. XU, Approximating curves of nonexpansive nonself mappings in Banach spaces, C. R. Acad. Sci., Paris, Ser. I, to appear. 